\title{
Erratum to: Quantitative accuracy of attenuation correction in the Philips Ingenuity TF whole-body PET/MR system: a direct comparison with transmission-based attenuation correction
}

\author{
Georg Schramm • Jens Langner • Frank Hofheinz • \\ Jan Petr • Bettina Beuthien-Baumann · Ivan Platzek • \\ Jörg Steinbach $\cdot$ Jörg Kotzerke $\cdot$ Jörg van den Hoff
}

Published online: 20 April 2014

(C) ESMRMB 2014

Erratum to: Magn Reson Mater Phy (2013) 26:115-126

DOI 10.1007/s10334-012-0328-5

Unfortunately, the online published article has errors in Table 2. In Table 2, in the row "clavicular region," the ranges should be -13 to $22 \%$ and -11 to $23 \%$ instead of -13 to $2 \%$ and -11 to $2 \%$.

The correct table is provided here.
Table 2 Relative differences (mean \pm standard deviation) between SUV $_{\text {MRAC }}$ and SUV $_{\text {TRAC }}$ in the liver, the cerebellum and several hot focal structure VOIs

\begin{tabular}{|c|c|c|c|c|c|c|c|}
\hline \multirow[t]{2}{*}{ VOI } & \multirow[t]{2}{*}{ Number } & \multicolumn{3}{|c|}{$\Delta \mathrm{SUV}_{\text {rel,max }}(\%)$} & \multicolumn{3}{|c|}{$\Delta \mathrm{SUV}_{\text {rel,mean }}(\%)$} \\
\hline & & Mean $\pm \mathrm{SD}$ & Median & Range & Mean \pm SD & Median & Range \\
\hline Liver & 9 & $-4 \pm 9$ & -5 & -18 to 8 & $-5 \pm 10$ & -7 & -20 to 12 \\
\hline Cerebellum & 4 & $12 \pm 6$ & 12 & 6 to 19 & $12 \pm 4$ & 12 & 8 to 17 \\
\hline \multicolumn{8}{|l|}{ Hot focal structures } \\
\hline Total & 49 & $-2 \pm 11$ & -6 & -17 to 22 & $-1 \pm 10$ & -4 & -16 to 23 \\
\hline $\begin{array}{l}\text { Lung and } \\
\text { mediastinum }\end{array}$ & 8 & $-13 \pm 3$ & -14 & -17 to -9 & $-13 \pm 3$ & -14 & -16 to -8 \\
\hline Thoracic spine & 18 & $-6 \pm 8$ & -8 & -16 to 19 & $-5 \pm 7$ & -6 & -12 to 15 \\
\hline Clavicular region & 18 & $7 \pm 9$ & 7 & -13 to 22 & $7 \pm 8$ & 6 & -11 to 23 \\
\hline Liver and kidney & 5 & $-1 \pm 6$ & -1 & -8 to 9 & $-1 \pm 6$ & -2 & -6 to 9 \\
\hline
\end{tabular}

The online version of the original article can be found under doi:10.1007/s10334-012-0328-5.

G. Schramm $(\bowtie) \cdot$ J. Langner · F. Hofheinz · J. Petr .

J. Steinbach - J. van den Hoff

PET Center, Institute of Radiopharmacy, Helmholtz-Zentrum

Dresden-Rossendorf, Dresden, Germany

e-mail: g.schramm@hzdr.de

B. Beuthien-Baumann · J. Kotzerke $\cdot$ J. van den Hoff Department of Nuclear Medicine, University Hospital

Carl Gustav Carus, Technische Univserität Dresden,

Dresden, Germany

I. Platzek

Department of Radiology, University Hospital Carl Gustav

Carus, Technische Universität Dresden, Dresden, Germany 